www.jmscr.igmpublication.org

Impact Factor 5.84

Index Copernicus Value: 83.27

ISSN (e)-2347-176x ISSN (p) 2455-0450

crossref DOI: _https://dx.doi.org/10.18535/jmscr/v5i6.04

Journal Of Medical Science And Clinical Research

\title{
Awareness Regarding Mother to Child Transmission of HIV among Antenatal Patients Attending Antenatal Clinic in a Tertiary Medical Hospital, Bangalore
}

\author{
Authors \\ Dr Harshadayani ${ }^{1}$, Dr Jagadevi ${ }^{2}$, Dr Padmashri ${ }^{3}$ \\ ${ }^{1}$ Intern Student, ${ }^{2}$ Senior Resident, ${ }^{3}$ Professor and Head of Department \\ Department of Obstetrics and Gynecology \\ Sapthagiri Institute of Medical Science And Research Centre, Bangalore
}

\begin{abstract}
Introduction: In India due to lack of information, testing services and antiretroviral therapy HIV continues to be a problem.1-4 Prevention of MTCT of HIV requires a comprehensive set of interventions requiring health workers.6-7 It starts with testing pregnant women for HIV preferably during their first antenatal visit when giving their test results .8-9

Aim: Evaluation of Awareness of perinatal transmission of HIV to newborn baby among antenatal mothers attending ANC clinic.

Objective: To assess knowledge regarding mother to child transmission of HIV among antenatal patients.

Material and Methods: Study design-It is a cross sectional study.

Study area- Tertiary care hospital.

Sampling method- Non probability convenience sampling.

Population - All pregnant women seeking for antenatal checkup, were interviewed, study was conducted for a period of 3 months.

Method of data collection-Interview method is used using a semi standardized pretested questionnaire.

Result: Our study shows that majority of antenatal women had good knowledge and awareness about the disease and its occurrence in pregnancy. Most were aware of sexual transmission was main route of transmission in adults with media playing major role as source of knowledge. Awareness about mother to child transmission of HIV and their prevention was low.

Conclusion: Our study shows that awareness about HIV in pregnancy in a semi urban area is high but knowledge and awareness about mother to child transmission of HIV is low.

Keywords- awareness, HIV, mother to child transmission ,Antenatal patients, prevention.
\end{abstract}

\section{INTRODUCTION}

Globally 40 million people were living with HIV in the year of 2016 which is $1 \%$ of population. ${ }^{1-3}$ In India due to lack of information, testing services and antiretroviral therapy HIV continues to be a problem. ${ }^{4}$ More than $90 \%$ of children who are retro positive aged less than 15 years are due to mother to child transmission. ${ }^{5}$ In developing countries mother to child transmission is responsible for 5 to $10 \%$ of total number of HIV. ${ }^{6}$ 
The risk of mother to child transmission can be reduced by prevention of unwanted pregnancy , new infection and awareness about mother to child transmission in HIV infected women .

Our study is intended to assess awareness among antenatal patients about mother to child transmission of HIV.

\section{REVIEW OF LITERATURE}

A descriptive study was conducted on 666 women seeking prenatal care at 9 medical facilities in Chennai and Mysore in India, to assess their attitudes towards prenatal HIV testing and antiretroviral prophylaxis for preventing perinatal HIV transmission if needed. $76 \%$ of antenatal were aware of the risk of perinatal HIV transmission and 36\% knew that intervention could reduce the chances of such transmission. $86 \%$ would agree to undergo prenatal HIV testing but only $21 \%$ of all antenatal mothers would make this decision independently while $46 \%$ said their husband would have to decide ${ }^{8}$.

A descriptive study was conducted in north western china with a population of 2 million. Out of total 290 pregnant women in their study they had limited knowledge about MTCT of HIV with several misconception. Awareness about HIV as sexually transmitted was well known but stigma remains high among high risk patients. The study implicated that it was important to provide information about HIV and its stigma to antenatal women in north western china. ${ }^{9}$ A descriptive study was conducted at the pediatric HIV clinic of Amiu Kano . Out of total 164 mothers the level of knowledge about HIV/AIDS among mothers was very high $(100 \%)$.Out of which $91 \%$ of mothers were aware of Mother-to-child transmission of HIV. Transplacental route $(41 \%)$ was the most common route of transmission. The level of knowledge and perceptions of Mother-to-child transmission of HIV was inadequate. The study concluded that there was a need to scale up education about Mother-to-child transmission of HIV in the health facilities ${ }^{10}$.
A cross sectional survey was conducted in Kep district of Cambodia in ten different villages among adults between the ages 18 to 58 years to assess the HIV/AIDS-related knowledge. The majority of respondents had an accurate knowledge about the modes of transmission and method of prevention of HIV but their understanding regarding mother-to-child transmission was low. ${ }^{11}$

A descriptive study was done to evaluate the Prevention of Mother-to-child transmission of HIV in Temeke district of Tanzania. The result showed that $68.1 \%$ of the participants had already had HIV testing but $31.9 \%$ had not. General knowledge of the participants about HIV was high, but specific knowledge of mother- to-child transmission was relatively low. ${ }^{12}$

A cross sectional study was conducted to evaluate the knowledge on mother-to -child transmission of HIV and its prevention among pregnant women attending antenatal clinic of a federal medical Centre in Ekiti State in Nigeria. The majority $(90 \%)$ of the women were aware that HIV/AIDS can coexist with pregnancy, but only $68 \%$ were aware of mother-to-child transmission. Transplacental route, vaginal delivery and breastfeeding were identified as routes of transmission from mother to child by $65 \%, 38 \%$ and $52 \%$ of respondents, respectively. Caesarean section was believed to be a route of transmission by $43 \%$ of women, but only $3 \%$ identified caesarean section as a method of prevention of mother-to-child transmission. The results suggested that though the level of awareness of HIV/AIDS among women attending their antenatal clinic was high, the level of knowledge about mother-to-child transmission was inadequate. ${ }^{13}$

A cross sectional study was conducted in Tehran, Iran to evaluate the knowledge of women about HIV and its vertical transmission and prevention among 1577 pregnant women aged 15 - 46 years. $16.5 \%$ of the participants had good knowledge about HIV/AIDS and $54.1 \%$ about its transmission routes but awareness about its prevention was only $5.7 \% .57 \%$ of the participants 
were not tested for HIV earlier and $20.2 \%$ were not willing to undergo such tests. About $86.2 \%$ of the participants had no idea about the availability of drug prophylaxis. The fact that $20.2 \%$ of the participants were not willing to undergo HIV testing reflects negative attitude about HIV infection. Although the overall awareness about the infection and its transmission was good, the knowledge about its prevention by prevention of mother-to-child transmission services and its availability was low. ${ }^{14}$

\section{AIM}

Evaluation of Awareness of perinatal transmission of HIV to newborn baby among antenatal mothers attending ANC clinic.

\section{OBJECTIVE}

To assess knowledge regarding mother to child transmission of HIV among antenatal patients.

\section{METHOD AND MATERIAL}

Study design- It is a cross sectional study.

Study area- Tertiary care hospital.

Sampling method- Non probability convenience sampling.

Population -All pregnant women who are coming to OBG department seeking for antenatal checkup for a duration of 3 months were interviewed.

Method of data collection - Interview method used using a semi standardized pretested questionnaire.

We explained about purpose of our study in their local language to facilitate better communication and volunteering. Volunteered ANC mothers were interviewed after taking oral consent from them.

Inclusion criteria: all antenatal patients between 19 to 40 years.

Exclusion criteria: < 19 years, > 40 years.

\section{RESULT}

Our study shows that out of 315 ANC women majority 310(98.4\%) were aware about disease, 5 $(1.6 \%)$ were not aware. Major source of information was the media $124(39.3 \%)$ by friends and relatives $77(24.5 \%)$, by hospital and health care workers 74(22.7\%) and others 44(13.5\%). Majority knew sexual transmission as the main route of transmission accounting for 135(42.9\%), followed by injections 48(15.8\%), blood transfusion 47(14.8\%), breastfeeding 42 (13.3\%), vaginal delivery $23(7.3 \%)$ and caesarean section $18(5.7 \%)$ respectively. HIV/AIDS was thought to be most common among multiple sexual partners $200(63.5 \%)$ and commercial sex workers 68 (34.7\%), followed by IV drug abusers 38(12.1). Of 315 ANC women290 (92.1\%) wished to have HIV test, 25(7.9\%) were not interested. Majority $270(85.7 \%)$ were aware about the occurrence of HIV in pregnancy and 58(18.4\%) aware of mother to child transmission but $45(14.3 \%)$ were not aware about occurrence of HIV in pregnancy and $257(81.6 \%)$ were not aware about mother to child transmission of HIV.214(67.9\%) were not aware about the methods to prevent mother to child transmission of HIV while,69(22.9\%) of women thought to avoid breastfeeding and rest $32(10.1 \%)$ opted for caesarean section. Majority of women $265(84.1 \%)$ were aware about the tests available to detect HIV and 257(87.3\%) had already got tested but 50(15.8\%) were not aware of the tests and $40(12.7 \%)$ did not have the tests. $168(53.3 \%)$ of antenatal women were not aware about the need for HAART and its significance but $147(46.7 \%)$ were aware about its significance. $167(53 \%)$ knew where centers for ICTC are present and 148(47\%) mentioned that they had not heard about it.238(75.6\%) mentioned that the rate of pregnant women with HIV is more in cities than $77(24.5 \%)$ in rural area because of their lifestyle and behavior. 207(65.7\%) thought that the present rate of mother to child transmission of HIV is increasing, 50(15.9\%) decreasing and $58(18.4 \%)$ same as before. 257(81.6\%) do not have any family members with AIDS while 25(7.9\%) did not want to enclose and 33(10.5\%) had family members who were infected. $215(68.3 \%)$ were willing to inform other hospital staff if test comes positive, $39(12.4 \%)$ were not 
willing and 61(19.4\%) did not know. 269(85.4\%) were willing to tell their husbands if test comes positive, $13140(44.4 \%)$ were ready to shorten the duration of breastfeeding to less than six months to reduce transmission to their child, $112(35.6 \%)$ were not ready and 63(20.6\%) didn't know.159 $(50.5 \%)$ did not want to have more children if test comes positive $77(24.4 \%)$ wanted more children and $79(25.1 \%)$ didn't know. Majority belong to 19-24 accounting for (50.8\%) and 25-30 (39.7\%) followed by $31-35$ and $36-40$ which was $(8.9 \%)$ and $(.6 \%)$ respectively. A total of $193(61.3 \%)$ belonged to rural and rest $122(38.7 \%)$ belong to urban area. Majority studied up to secondary school $(45.1 \%)$ followed by university, college, illiterate which was (23.8\%),(18.7\%),(12.4\%) respectively .Married women are 301(95.6\%) and single women $14(4.4 \%) 247(78.6 \%)$ of women are housewives and others 68(21.6\%) are working outside.

\section{DISCUSSION}

In our study media $124(39.3 \%)$ were the main sources of information about HIV/AIDS. In Sevanan Murajan et al (2010)29 194(64.6\%) television was the main source of information about HIV . In our study a substantial number of women also reported having had conversation with others about HIV/AIDS most frequently with friends and relatives $(24.5 \%)$ but also with health and education professional $(22.7 \%)$ and others (13\%). Lal $\mathrm{P}$ et al(2008)31 studied $79.6 \%$ mentioned television and radio were the main sources of information to them. In the present study $135(42.9 \%)$ mentioned sexual route ,14.8\% and $15.8 \%$ name blood transfusion and needles as mode of transmission, $13.3 \%$ breastfeeding , $5.7 \%$ caesarean and $7.3 \%$ vaginal delivery as route of transmission. This is comparable with Lal p et al (2008)31 only $48.2 \%$ could name sexual route while $44.4 \%$ mention sharing of needles and syringes as mode of transmission. Only $31.1 \%$ and $23.4 \%$ cited blood transfusion and mother to child transmission as route of transmission respectively. Majority $85.9 \%$ of the women were aware that
HIV infection could coexist with pregnancy but very low proportion (63.2\%) of respondents were aware of mother-to child transmission of HIV. This shows their poor knowledge of MTCT HIV inspite of good knowledge about its coexistence with pregnancy. The study also reveals that illiterate or literate up to primary level respondents had poor knowledge about mother-tochild transmission of HIV while $87.6 \%$ literate had good knowledge about mother to child transmission. This statistically significant relationship between the level of education and knowledge of HIV was also found in Bassey et al (2009) 32 and could partly be explained by the fact that highly educated people usually have more access to information including that on HIV .In India and other developing countries, breastfeeding is given more importance culturally and exclusive breastfeeding for six months is advocated this reduces high infant mortality and morbidity from diarrheal diseases and malnutrition. This can be encouraged by providing milk substitutes free of cost by both government and non government agencies. In our study $50.5 \%$ of ANC mothers did not want to have children in the future and $24.4 \%$ wanted to have children in future. The desire to have child was much lower $24.4 \%$ compared to $70 \%$ of pregnant mothers expressing their desire to have children (Ezeanoule et al., 2006) which shows their better awareness .In our study majority 160(50.8\%) women belongs to 19-24 years age group, $125(39.7 \%)$ belongs to $25-29$ years age group and $28(8.9 \%)$ belongs to $30-34 y r s$ and $(.6 \%)$ belong to $35-40 y r s$.Majority were below 25 years. This was comparable with shrotri A et al (2003)30 i.e. $45(30.00 \%)$ women belongs to18-20 years age group, $81(54.00 \%)$ belongs to $21-25$ years age group and $24(16.00 \%)$ belongs to 26 and above years age group. Out of 315 ANC women $247(78.4 \%)$ were housewives and 68(21.6\%) belong to other occupation. In Shrotri A et al (2003)30out of total 707 women 584 (83\%) were housewives and 123(17\%) belongs to other occupations. In the present study out of 315 ANC 
client 29(9.2\%) were having education up to Primary school, 142(45.1\%) studied up to secondary school, 134(42.5\%) studied up to Higher secondary above and 10(3.2\%) were illiterate. The finding were similar with Shrotri A et al (2003)30out of 707, 230(33\%) were educated up to illiterate/primary, $477(67 \%)$ were educated up to secondary and above. This shows that education plays very important role in their knowledge about HIV .For community education, a public media campaign should stress more on the aspect of prevention of mother-to-child transmission. There is also the need for increased collaboration with HIV prevention programs.

\section{TABLE 1}

\begin{tabular}{|c|c|c|}
\hline & Frequency $=\mathrm{n}$ & Percentage $\%$ \\
\hline \multicolumn{3}{|l|}{ Q1-Heard about HIV } \\
\hline Yes & 310 & 98.4 \\
\hline No & 2 & .6 \\
\hline Don't know & 3 & 1 \\
\hline Total & 315 & 100 \\
\hline \multicolumn{3}{|l|}{ Q2-Source of information } \\
\hline media & 124 & 39.3 \\
\hline Friends & 77 & 24.5 \\
\hline Relatives & 74 & 22.7 \\
\hline others & 41 & 13 \\
\hline total & 315 & 100 \\
\hline \multicolumn{3}{|l|}{ Q3-Route of transmission } \\
\hline Vaginal & 23 & 7.3 \\
\hline Caesarean section & 18 & 5.7 \\
\hline Breastfeeding & 135 & 42.9 \\
\hline Sexual route & 42 & 13.3 \\
\hline Blood transfusion & 47 & 14.8 \\
\hline Injections & 48 & 15.8 \\
\hline Total & 315 & 100 \\
\hline \multicolumn{3}{|l|}{$\begin{array}{l}\text { Q4-Population most } \\
\text { commonly affected }\end{array}$} \\
\hline Men having sex with men & 9 & 2.8 \\
\hline Multiple sexual partner & 200 & 63.1 \\
\hline IV drug abusers & 38 & 12.1 \\
\hline Commercial sex worker & 68 & 34.7 \\
\hline Total & 315 & 100 \\
\hline
\end{tabular}

TABLE -2

\begin{tabular}{|c|c|c|}
\hline Q5-Wish to find HIV in blood & frequency $=n$ & percentage $=\%$ \\
\hline Yes & 290 & 92.1 \\
\hline No & 25 & 7.9 \\
\hline Total & 315 & 100 \\
\hline \multicolumn{3}{|l|}{$\begin{array}{l}\text { Q6-Aware of occurrence of HIV } \\
\text { in pregnancy }\end{array}$} \\
\hline Yes & 270 & 85.7 \\
\hline No & 19 & 6 \\
\hline Don't know & 26 & 8.3 \\
\hline Total & 315 & 100 \\
\hline \multicolumn{3}{|l|}{ Q7-Aware about MTCT } \\
\hline Yes & 199 & 63.2 \\
\hline No & 58 & 18.4 \\
\hline Don't know & 58 & 18.4 \\
\hline Total & 315 & 100 \\
\hline \multicolumn{3}{|l|}{$\begin{array}{lll}\text { Q8-Aware } & \text { about } & \text { MTCT } \\
\text { prevention }\end{array}$} \\
\hline Caesarean section & 32 & 10.1 \\
\hline Avoid breastfeeding & 69 & 22.9 \\
\hline Don't know & 214 & 67.9 \\
\hline Total & 315 & 100 \\
\hline
\end{tabular}

TABLE 3

\begin{tabular}{|l|c|c|}
\hline Q9-Aware about tests for HIV & frequency=n & $\%$ \\
\hline Yes & 265 & 84.1 \\
\hline No & 19 & 6 \\
\hline Don't know & 31 & 9.8 \\
\hline Total & 315 & 100 \\
\hline Q10-Already got tested & & \\
\hline Yes & 275 & 87.3 \\
\hline No & 40 & 12.7 \\
\hline Total & 315 & 100 \\
\hline Q11-Aware about need for HAART & & \\
\hline Yes & 147 & 47.6 \\
\hline No & 87 & 27.6 \\
\hline Don't know & 81 & 25.7 \\
\hline Total & 315 & 100 \\
\hline Q12-Aware about where ICTC is present & & \\
\hline Yes & 167 & 53 \\
\hline No & 106 & 33.7 \\
\hline Don't know & 42 & 13.3 \\
\hline Total & 315 & 100 \\
\hline
\end{tabular}




\section{TABLE-4}

\begin{tabular}{|c|c|c|}
\hline Q13-HIV in pregnancy & frequency $=n$ & percentage $=\%$ \\
\hline More in city & 238 & 75.5 \\
\hline More in rural & 77 & 24.5 \\
\hline Total & 315 & 100 \\
\hline \multicolumn{3}{|c|}{ Q14-Rate of HIV in pregnancy } \\
\hline Increasing & 207 & 65.7 \\
\hline Decreasing & 50 & 15.9 \\
\hline Same & 58 & 18.4 \\
\hline Total & 315 & 100 \\
\hline \multicolumn{3}{|c|}{ Q15-Family/friend with HIV } \\
\hline Yes & 33 & 10.5 \\
\hline No & 257 & 81.6 \\
\hline Don't know & 25 & 7.9 \\
\hline Total & 315 & 100 \\
\hline \multicolumn{3}{|c|}{$\begin{array}{l}\text { Q16-Inform hospital staff if HIV } \\
\text { positive }\end{array}$} \\
\hline Yes & 215 & 68.3 \\
\hline No & 39 & 12.4 \\
\hline Don't know & 61 & 19.4 \\
\hline Total & 315 & 100 \\
\hline
\end{tabular}

\section{TABLE-5}

\begin{tabular}{|l|c|c|}
\hline $\begin{array}{l}\text { Q17-Will you inform husband } \\
\text { if you tested } \\
\text { HIV positive }\end{array}$ & frequency=n & percentage=\% \\
\hline Yes & 269 & 85.4 \\
\hline No & 13 & 4.1 \\
\hline Don't know Shorten & 33 & 10.5 \\
\hline Total you avoid & 315 & 100 \\
\hline $\begin{array}{l}\text { Q18- Will } \\
\text { duration breastfeeding to ansmission } \\
\text { trans }\end{array}$ & 140 & 44.4 \\
\hline Yes & 112 & 35.6 \\
\hline No more & 63 & 20 \\
\hline Don't know positive & 315 & 100 \\
\hline Total & 77 & 24.4 \\
\hline $\begin{array}{l}\text { Q19-Want to have } \\
\text { children even if HIV }\end{array}$ & 159 & 50.5 \\
\hline Yes & 79 & \\
\hline No & & \\
\hline Don't know & & \\
\hline total & & \\
\hline
\end{tabular}

TABLE-6 Sociodemographic Character

\begin{tabular}{|c|c|c|}
\hline Q20-Age & frequency $=n$ & percentage $=\%$ \\
\hline $19-24$ & 160 & 50.8 \\
\hline $25-30$ & 125 & 39.7 \\
\hline $31-35$ & 28 & 8.9 \\
\hline $36-40$ & 2 & .6 \\
\hline total & 315 & 100 \\
\hline \multicolumn{3}{|l|}{ Q21-Place } \\
\hline \multirow{2}{*}{$\begin{array}{l}\text { Rural } \\
\text { Urban }\end{array}$} & 122 & 37.7 \\
\hline & 193 & 61.3 \\
\hline Total & 315 & 100 \\
\hline \multicolumn{3}{|c|}{ Q22-Eduction } \\
\hline University & 75 & 23.8 \\
\hline College & 59 & 18.7 \\
\hline Secondary & 142 & 45.1 \\
\hline Illiterate & 39 & 12.4 \\
\hline Total & 315 & 100 \\
\hline \multicolumn{3}{|l|}{ Q23 } \\
\hline Married & 301 & 95.6 \\
\hline Single & 14 & 4.4 \\
\hline Total & 315 & 100 \\
\hline \multicolumn{3}{|c|}{ Q24-Occcupation } \\
\hline Housewife & 247 & 78.4 \\
\hline \multicolumn{3}{|l|}{\begin{tabular}{|l|} 
Others \\
21.1
\end{tabular}} \\
\hline Total & & 315 \\
\hline
\end{tabular}

\section{Implication}

In order to reduce vertical transmission of HIV to infants who play a major part of futures health of society there should be increase in the number of counselling centers and health workers especially in rural and semi urban areas to reduce misconception, specific awareness programmes to be implemented by government free of cost for a healthy future.

\section{CONCLUSION}

Our study shows that awareness about HIV in pregnancy in a semi urban area is high but knowledge and awareness about mother to child transmission of HIV is low. This study shows the 
stigma and lack of awareness about the significance of vertical transmission of HIV among antenatal mothers for which immediate measures has to be taken by both government and health care organization which is both easily accessible and affordable for the betterment of the future.

\section{REFERENCES}

1. Laval B O. HIV/AIDS awareness among secondary school teachers in Kwara logos andagun states of Nigeria. European Journal of scientific research.22 (3), 2008,339-410.

2. ParkK. Textbook of Preventive and Social Medicine. 21th edi. M/s Banarasidas Bhanot publishers; 2011 .

3. UNAIDS(2016) global HIV/AIDS response; $\mathrm{e}$ pidemic update and health sector progress towards universal access; progress report november 2016.world health organisaton, Geneva 233.

4. Joint United Nations Programme on HIV/AIDS (UNAIDS).Report on the globalAIDS

5. epidemic2016.Availablefrom;http://www.u naids.org/en/KnowledgeCentre/HIVData/ GlobalReport/2016/2016_Global_report.as $\mathrm{p}$ [accessed on 2016 November].

6. NationalAIDSControlOrganisation

(NACO). Annual HIV Sentinel Surveillance Country Report 2006. Available

from:http://www.nacoonline.org/upload/ [accessed on 2010 Mar 168.No Author, 50 Lakhs Indians HIV positive.The Tribune Jan 10, 2005.

7. DalarAR.prevention of mother to child transmission of HIV/AIDS infection .j of obstetric and gynecology of India ,2001;51:25-27.

8. McIntyre J, Glenda G. What can we do to reduce mother to child transmission of HIV?British Medical Journal 2002; 324: 218-220.
9. Brown $\mathrm{H}$, Vallabhaneni $\mathrm{S}$, Solomon $\mathrm{S}$, Mothi S, McGarvey S, Jackson T, Putcha $\mathrm{M}$, Burner $\mathrm{S}$, Mate $\mathrm{K}$ and $\mathrm{Cu}-\mathrm{Uvin} \mathrm{S}$. 2001. Attitudes towards prenatal HIV testing and treatment among pregnant woman in southern India. International Journal of STD \& AIDS 2001:12:390-394 doi 10. 1258/0956462011923345.

10. Maimiti R., Anderson R. Awareness and Attitude About HIV Among Pregnant Women in Aksu, Northwest China. The Open AIDS Journal 2008; 2:72-77.

11. Adeleke S.I., Mukhtar-Yola M., Gwarzo G.D. Awarness and knowledge of mothers attending the pediatric HIV clinic, Kano, Nigeria. Annals of African Medicine 2009 (4) 210-214.

12. Ho EY and Grewal S. HIV/AIDS-Related Knowledge, Attitudes, and Practices of a Rural Community in Kep, Kingdom of Cambodia. Univ Tor Med J. 2005 Mar;82(2):82-87.

13. Kominami M., Kawata K., Ali M.,Meena H., Ushijima H. 2007 , “ Factors determining parental HIV testing for prevention of mother to child transmission in Dar Salaam, Tanzania Pediatrics international volume49,issue 21,pages 286-292 Blackwell publishing Asia. http://www3.interscience.wiley .com/journal/ 118514482/abstract

14. Moses O. Abiodun, Munir'deen A, and Peter A. Aboyeji. Awareness and Knowledge of mother-to-child transmission of HIV among pregnant women. J Natl Med Assoc. 2007 July; 99(7):758-763.

15. Richad H. 2009. Virology - Chapter Seven Part Five. Human Immunodefiency Virus and Aids Statistics. http:// pathmicro.med.sc.edu .

16. Sandgren E, Sandgren S, Ueazalin M, Andersson R. HIV/AIDS awareness and risk behavior among pregnant women in Samey, Kaazakhstan,2007. BMC Public 
Health.2008; 8: 295 doi 10.1186/1471-

PMC 2543023.

17. MurajanS,Saberrimuthis, Pongiya V, Desigan CG. Awareness about HIV/AIDS among adolescent boys in tribal villages of nilgiri district south India. Humanity and social sci. J; 5(1):63-67.

18. Lal P, NathA,bandhanS, IngleGK. The study of awareness about HIV/AIDS among senior secondary school children of Delhi. Indian journal of community medicine, 33(3), 2010,190-192.

19. Bassey E.A.,Abasiubang F, Ekanem U, Abasiatai. Awareness and knowledge of HIV/AIDS at booking among antenatal clinic attendees in UYO ,Nigeria Int.J.med.med.sci.,1(8),2009,334-338. 